\title{
TU/e emonownen

\section{Design aspects of an active electromagnetic suspension system for automotive applications}

\section{Citation for published version (APA):}

Gysen, B. L. J., Janssen, J. L. G., Paulides, J. J. H., \& Lomonova, E. A. (2008). Design aspects of an active electromagnetic suspension system for automotive applications. In IAS '08 : IEEE Industry Applications Society annual meeting, 2008 ; 5 - 9 Oct. 2008, Edmonton, Alberta, Canada (pp. 1-8). Institute of Electrical and Electronics Engineers. https://doi.org/10.1109/08IAS.2008.181

DOI:

10.1109/08IAS.2008.181

Document status and date:

Published: 01/01/2008

\section{Document Version:}

Publisher's PDF, also known as Version of Record (includes final page, issue and volume numbers)

\section{Please check the document version of this publication:}

- A submitted manuscript is the version of the article upon submission and before peer-review. There can be important differences between the submitted version and the official published version of record. People interested in the research are advised to contact the author for the final version of the publication, or visit the $\mathrm{DOI}$ to the publisher's website.

- The final author version and the galley proof are versions of the publication after peer review.

- The final published version features the final layout of the paper including the volume, issue and page numbers.

Link to publication

\section{General rights}

Copyright and moral rights for the publications made accessible in the public portal are retained by the authors and/or other copyright owners and it is a condition of accessing publications that users recognise and abide by the legal requirements associated with these rights.

- Users may download and print one copy of any publication from the public portal for the purpose of private study or research.

- You may not further distribute the material or use it for any profit-making activity or commercial gain

- You may freely distribute the URL identifying the publication in the public portal.

If the publication is distributed under the terms of Article 25fa of the Dutch Copyright Act, indicated by the "Taverne" license above, please follow below link for the End User Agreement:

www.tue.nl/taverne

Take down policy

If you believe that this document breaches copyright please contact us at:

openaccess@tue.nl

providing details and we will investigate your claim. 


\title{
Design Aspects of an Active Electromagnetic Suspension System for Automotive Applications
}

\author{
Bart L.J. Gysen, Jeroen L.G. Janssen, Johannes J.H. Paulides, Elena A. Lomonova \\ Eindhoven University of Technology \\ Department of Electrical Engineering \\ Eindhoven, The Netherlands \\ Email: B.L.J.Gysen@tue.nl
}

\begin{abstract}
This paper is concerned with the design aspects of an active electromagnet suspension system for automotive applications which combines a brushless tubular permanent magnet actuator (TPMA) with a passive spring. This system provides for additional stability and safety by performing active roll and pitch control during cornering and braking. Furthermore, elimination of the road irregularities is possible, hence passenger drive comfort is increased. Based upon measurements, static and dynamic specifications of the actuator are derived. The electro magnetic suspension is installed on a quarter car test setup, and the improved performance using roll control is measured and compared to a commercial passive system. An alternative design using a slotless external magnet tubular actuator is proposed which fulfills the derived performance, thermal and volume specifications.
\end{abstract}

\section{INTRODUCTION}

In future, active suspension systems will replace conventional passive suspension systems since vehicle stability and passenger safety is a high concern for car designers. Cars tend to become smaller (SMART), incorporate a higher center of gravity (SUV) and a reduced footprint, which increases the need for a suspension system with a rigid response when driving into turns while absorbing the road irregularities when driving under low-yaw circumstances (relatively straight). Currently, commercial systems consist of hydraulic or pneumatic actuators (for example installed on Citroen, Rolls-Royce, Mercedes Benz, etc.) which offer a high force density and ease in design due to the commercial availability of the various parts. However, these systems have a relatively low bandwidth (around 1Hz) [1], [2] probably due to leakage in the valves and pressure hoses and limited bandwidth of the pump. Furthermore, these systems are inefficient due to the need for a continuous pressurized system. In general, electromagnetic suspension systems have a very small response time and are therefore more suitable to absorb road vibrations and to react in lane change maneuvers. An example of a commercial electromagnetic semi-active suspension system is the magnetorheological damper [3], [4], developed by Delphi Cooperation (installed on Audi, Cadillac, Ferrari), which has the ability of changing its damper characteristic within $1 \mathrm{~ms}$ [5]. However, since it is a semi-active system, no active force can be applied and therefore, total roll and pitch elimination is impossible. This paper proposes an electromagnetic active suspension system comprising of a brushless tubular permanent

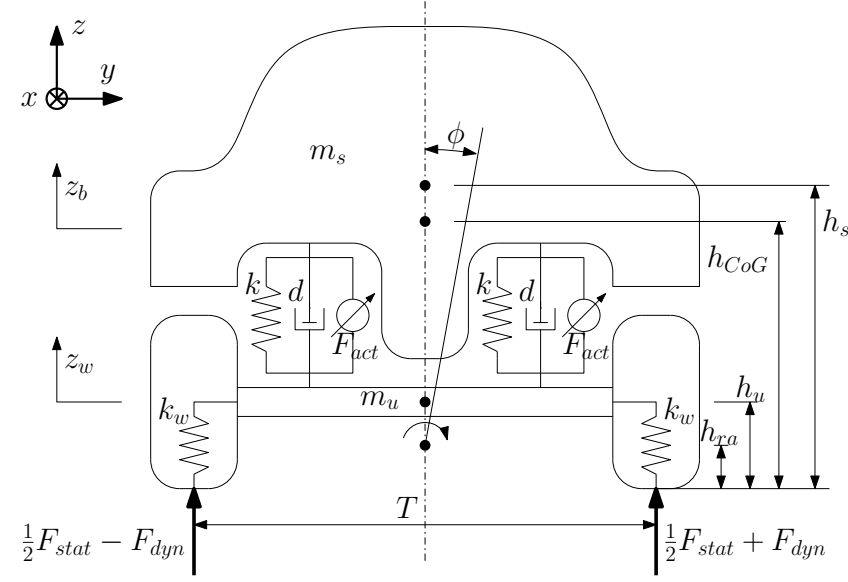

Fig. 1. Half car model for calculation of the roll forces.

magnet actuator (TPMA) [6], [7], in parallel with a mechanical spring [8], [9]. These actuators have a relatively high force density due to the tubular structure and excellent servo characteristics with a bandwidth in excess of $50 \mathrm{~Hz}$. Furthermore, electromagnetic actuators allow for bidirectional power flow and hence, both motor and generator modes are possible. The former is used to apply active forces on the sprung mass to eliminate roll and pitch movements, and the latter is used to absorb road vibrations and act as a damper where the absorbed power can be fed to the battery in order to supply auxiliary loads. Actuator force specifications will be derived in Section II based upon vertical acceleration measurements during a test drive on the Nürburgring. In Section III, the proof of principle will be shown by means of measurements on an inhouse designed and built quarter car test setup which mimics the roll behavior. Since a redesign of the total suspension is an expensive solution, this paper proposes a 'plug and play' suspension system in Section IV, which means that the volume specifications are based upon the currently installed passive suspension systems for both low voltage (general cars) and high voltage applications (hybrid cars). A slotless tubular permanent magnet actuator is proposed in Section $\mathrm{V}$ where it is shown that, by means of optimization, the inverted Halbach magnetized topology offers the highest force density. 


\section{SYSTEM SPECIFICATIONS}

In order to design a suspension system capable of eliminating roll and pitch behavior, it is necessary to identify the forces acting on the unsprung and sprung mass. As an example, during fast cornering, centrifugal forces tend to roll the car around the roll axis which causes an unbalance of the load or a load transfer from the inner to the outer wheels.

In such an example, using Fig. 1, the vertical dynamic force on the tires can be calculated as, [10],

$$
F_{d y n}=\left(m_{s}+m_{u}\right) a_{y} \frac{h_{C o G}}{T},
$$

where $a_{y}$ is the centrifugal acceleration during cornering. The vertical forces exerted on the tires by the unsprung mass, $F_{u}$, and sprung mass, $F_{s}$, can be calculated as

$$
\begin{aligned}
& \text { Front: } F_{u_{f}}=m_{u_{f}} a_{y} \frac{h_{u}}{T}, \\
& F_{s_{f}}=\psi_{m} m_{s} a_{y} \frac{h_{r a}}{T}, \\
& F_{a c t_{f}}=\frac{1}{C_{f}}\left(\gamma_{f} F_{d y n}-F_{u_{f}}-F_{s_{f}}\right) \text {, } \\
& \text { Rear: } F_{u_{r}}=m_{u_{r}} a_{y} \frac{h_{u}}{T} \text {, } \\
& F_{s_{r}}=\left(1-\psi_{m}\right) m_{s} a_{y} \frac{h_{r a}}{T}, \\
& F_{a c t_{r}}=\frac{1}{C_{r}}\left(\left(1-\gamma_{f}\right) F_{d y n}-F_{u_{r}}-F_{s_{r}}\right) \text {, }
\end{aligned}
$$

where $m_{u_{f}}$ and $m_{u_{r}}$ are the unsprung masses of the front and rear axle respectively and $\psi_{m}$ is the ratio of the total sprung mass acting on the front axle. Due to the independence of the actuators, it is possible to introduce a force ratio, $\gamma_{f}$, between front and rear axle which gives the possibility to control for understeer compared to the more dangerous oversteer behavior. The force ratios, $C_{f}$ and $C_{r}$, are introduced since the struts are not exactly vertical mounted. In order to calculate the actuator forces, the lateral acceleration, $a_{y}$, is measured during a one lap test drive with a BMW 530 on the Nürburgring in Germany and the actuator forces are calculated using the parameters of Table I. A short interval of these measurements is shown in Fig. 2, where, to eliminate the roll angle and using the complete data set, a peak and rms force of $4 \mathrm{kN}$ and $2 \mathrm{kN}$, respectively, are derived for the front actuators. As a comparison, Martins [11], showed that, an rms force of $1050 \mathrm{~N}$ is necessary to achieve the 'reduced comfort boundary', which is a $67 \%$ improvement compared to the standard ISO 2631 levels.

However, in general, passenger cars are not designed for continuously driving under these conditions and it can be assumed that the previous derived force levels should be attained with a duty cycle around $50 \%$. The continuous force level is therefore assumed to be $1 \mathrm{kN}$ for total roll and pitch elimination, with a peak force of $4 \mathrm{kN}$. Note that these force specification are only necessary at low vertical speed $(<0.1 \mathrm{~m} / \mathrm{s})$.

Next to roll and pitch requirements, the actuator should still be capable of delivering the required damping force, note that

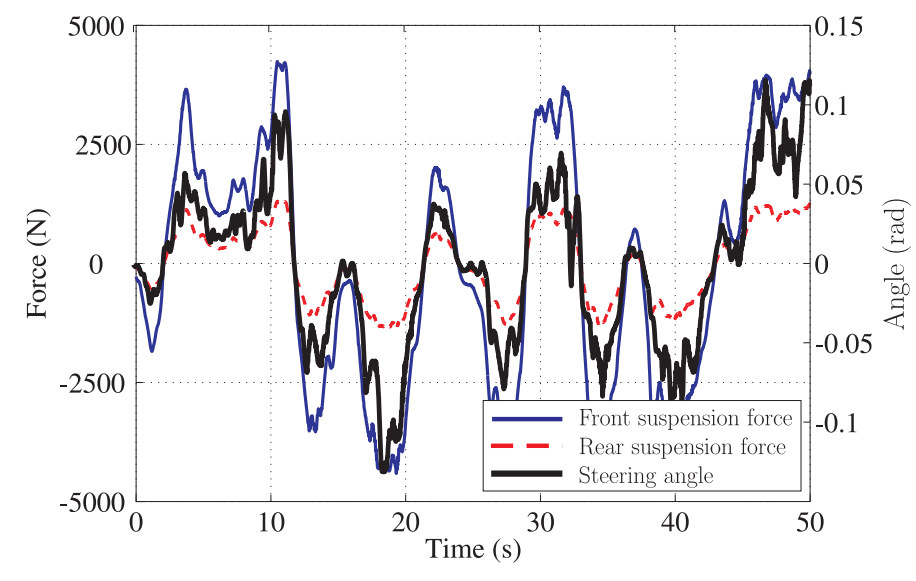

Fig. 2. Roll forces calculated from the measured lateral acceleration on the Nürburgring together with the measured steering angle.

TABLE I

PARAMETERS OF THE TEST VEHICLE.

\begin{tabular}{|l|l|l|}
\hline Parameter & Value & Description \\
\hline$m_{s}$ & $1613 \mathrm{~kg}$ & Sprung mass \\
$m_{u_{f}}$ & $96.6 \mathrm{~kg}$ & Front unsprung mass \\
$m_{u_{r}}$ & $89.8 \mathrm{~kg}$ & Rear unsprung mass \\
$h_{C o G}$ & $0.544 \mathrm{~m}$ & Center of gravity height \\
$h_{r a}$ & $8.98 \mathrm{~cm}$ & Roll axis height \\
$h_{u}$ & $0.31 \mathrm{~m}$ & Wheel axle height \\
$T$ & $1.57 \mathrm{~m}$ & Track width \\
$\phi_{m}$ & $50.9 \%$ & Front/total mass ratio \\
$\lambda_{f}$ & 0.7 & Front/total roll force distribution ratio \\
$C_{f}$ & 0.925 & Front suspension force ratio \\
$C_{r}$ & 0.98 & Rear suspension force ratio \\
\hline
\end{tabular}

in this case the actuator works in generator mode and energy is subtracted from the system to drive auxiliary loads or to charge the battery. When a load is applied to the actuator due to road vibration, a voltage will be induced resulting in a current flow through a variable load and therefore a variable opposed force is applied against the vibration forces and hence, a variable damping effect is achieved. The actuator should be capable of handling the amount of current within the thermal constraints of the system. In Fig. 3 the measured damping characteristic of the passive damper is shown. The actuator should be capable of absorbing these damping forces. Furthermore, it is assumed that all speeds from -1 until $1 \mathrm{~m} / \mathrm{s}$ occur with the same probability. Hence, an average of the absolute value of the nominal graph is a measure for the necessary continuous damping force, which is $762 \mathrm{~N}$ in this case with a maximum force of $2.05 \mathrm{kN}$ at $1 \mathrm{~m} / \mathrm{s}$. Although the actuator only needs a short-stroke capability for roll and pitch behavior, it still needs a long-stroke for absorbing the road irregularities. For this reason, the stroke specifications are comparable with the passive suspension system. As mentioned before, the volume specifications are such that the active suspension strut can replace the passive one without drastically changing the car design as will be discussed in Section IV. Regarding power constraints, the temperature increase of the actuator should be limited to $80{ }^{\circ} \mathrm{C}$ which means that together with an ambient temperature that can reach $40{ }^{\circ} \mathrm{C}$, the actuator's 


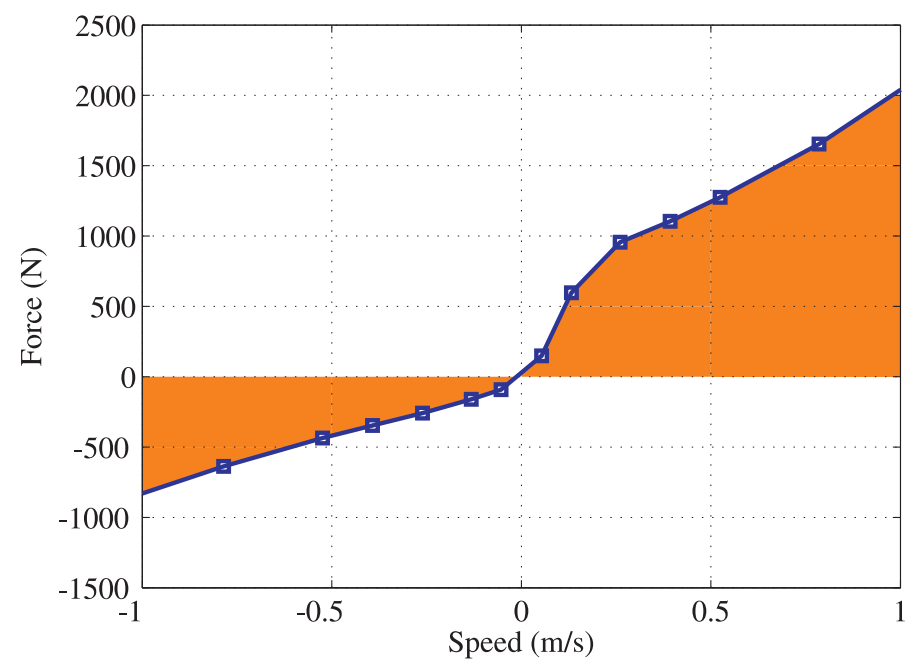

Fig. 3. Nominal damping characteristic of the passive damper and the working area for the active suspension.

TABLE II

SPECIFICATIONS OF THE SUSPENSION SYSTEM.

\begin{tabular}{|l|l|l|}
\hline Specification & Value & Description \\
\hline$F_{\text {rms roll }}$ & $1000 \mathrm{~N}$ & Rms force at $0.1 \mathrm{~m} / \mathrm{s}$ for active roll control \\
$F_{\max \text { roll }}$ & $4000 \mathrm{~N}$ & Max. force at $0.1 \mathrm{~m} / \mathrm{s}$ for active roll control \\
$F_{\text {rms damp }}$ & $762 \mathrm{~N}$ & Rms force at $1 \mathrm{~m} / \mathrm{s}$ for active damping \\
$F_{\max }$ damp & $2050 \mathrm{~N}$ & Max. force at $1 \mathrm{~m} / \mathrm{s}$ for active damping \\
$\Delta T_{\max }$ & $80^{\circ} \mathrm{C}$ & Maximum increase in temperature \\
$v_{\max }$ & $1 \mathrm{~m} / \mathrm{s}$ & Maximum speed \\
$z_{\max }$ & $140 \mathrm{~mm}$ & Minimum stroke \\
\hline
\end{tabular}

actual temperature will not exceed $120^{\circ} \mathrm{C}$ which is a standard limiting temperature in automotive engineering.

\section{QUARTER CAR TEST SETUP}

In order to verify the increased performance of the electromagnetic suspension system, measurements are performed on a quarter car test setup. Although roll and pitch are a coupled behavior, they can be modeled as a disturbance force acting on each of the four corners of a vehicle. This simplification leads to the ability of decoupling each corner of the car, resulting in a quarter car model. During cornering and braking, it is assumed that the unsprung mass movement is relatively small and therefore wheel dynamics are neglected which simplifies the setup to a single moving quarter car mass, see Fig. 4 and 5. Mimicking of cornering and braking will be performed by applying a body force, $F_{b o d y}$, see Fig. 6 , of $1920 \mathrm{~N}$ to the quarter car mass during a time interval which is typically around 3 seconds as obtained from the measurements on the Nürburgring. An industrial brushless tubular permanent magnet actuator [12] is used, which does not satisfy volume, mass and voltage constraints, however is still suitable for determine the functioning and performance of an electromagnetic suspension system.

In this setup, the position and speed of the quarter car mass are measured with an optical triangulation sensor, however, in practice, not the displacement but the roll angle needs to be

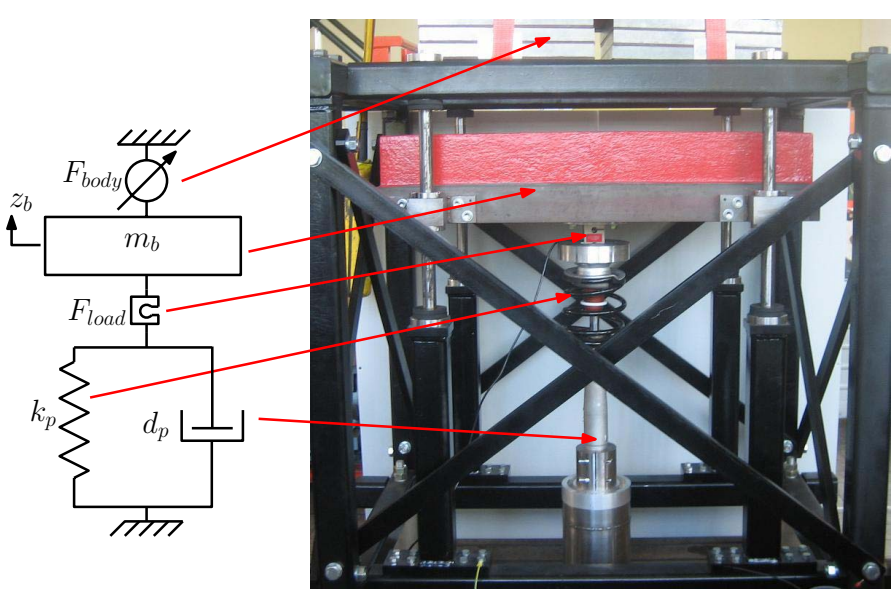

Fig. 4. Schematic view and illustration of the quarter car test setup with a passive suspension.

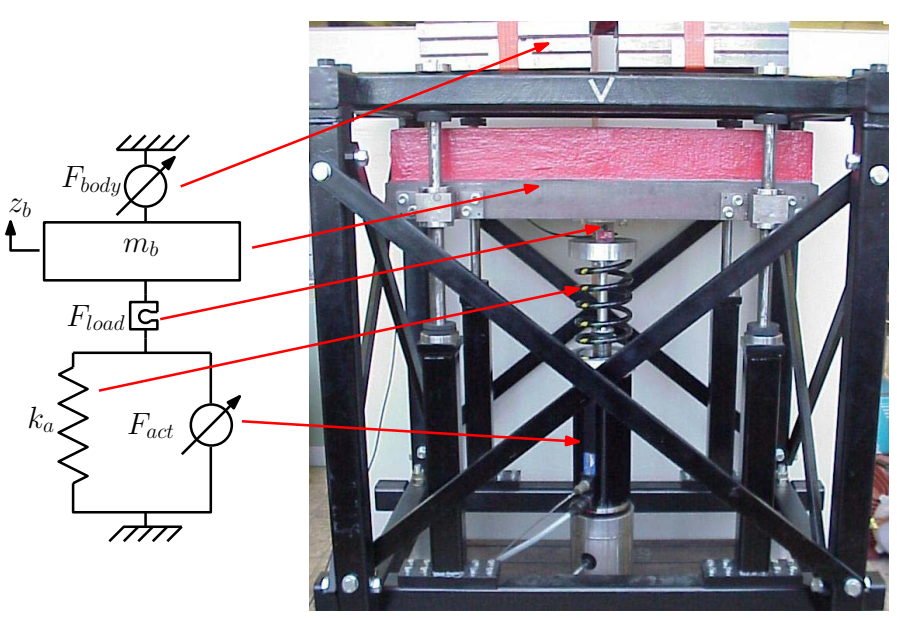

Fig. 5. Schematic view and illustration of the quarter car test setup with an active electromagnetic suspension.

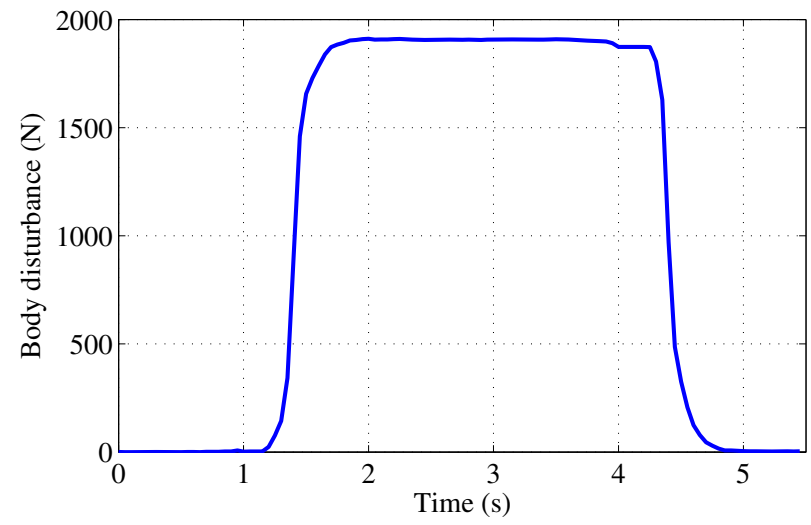

Fig. 6. Load profile of the body load applied to the quarter car mass. 
TABLE III

PARAMETERS OF THE QUARTER CAR TEST SETUP.

\begin{tabular}{|l|l|l|}
\hline Parameter & Value & Description \\
\hline$m_{b}$ & $387 \mathrm{~kg}$ & Quarter car mass \\
$k_{p}$ & $29.1 \mathrm{kN} / \mathrm{m}$ & Spring constant of the passive suspension \\
$d_{p}$ & see Fig. 3 & Passive damper characteristic \\
$k_{a}$ & $31.2 \mathrm{kN} / \mathrm{m}$ & Spring constant of the active suspension \\
$F_{\text {body }}$ & see Fig. 6 & Body force \\
\hline
\end{tabular}

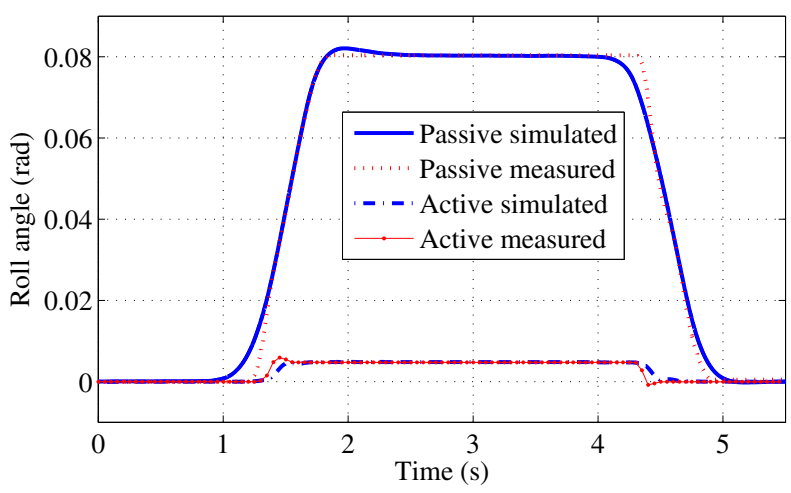

Fig. 7. Passive and active roll control measurements

measured. For this setup, the roll angle, $\phi$, is related to the position of the sprung mass, $z_{b}$, as

$$
\phi=\arctan \left(\frac{2 z_{b}}{T}\right) .
$$

Furthermore, a force sensor is incorporated in order to identify the load profile of the applied body force. The control and signal processing are performed with Matlab - dSpace software and hardware, where depending on the proportional gain of the controller, the body displacement can be minimized at the expense of power consumption. The parameters of the setup are given in Table III. In Fig. 7, the simulated and measured responses of the passive and active suspension system on the body force are shown. It can be observed that the electromagnetic suspension system immediately reacts on the applied force and the roll angle is minimized up to $5.9 \%$ of the passive roll angle. This provides for a trade off between allowable roll and power consumption. For example, if zero body roll is obtained, no mechanical energy is produced, hence speed dependent losses can be neglected. The steepness of the actuator, $S=\frac{F_{c c t}^{2}}{P_{c u}}$, where $P_{c u}$ are the copper losses, is $579 \mathrm{~N}^{2} / \mathrm{W}$ and hence the power as function of the body force and roll angle, $\phi$, can approximately be written as

$$
P_{c u} \approx \frac{\left(F_{b o d y}-\frac{k_{a} T \tan (\phi)}{2}\right)^{2}}{S} .
$$

To achieve zero body roll $636 \mathrm{~W}$ is necessary per wheel for the body disturbance of $1920 \mathrm{~N}$. However, taking into account the specified duty cycle of $50 \%$, the continuous power is $318 \mathrm{~W}$ per wheel, which is still a high power demand and therefore an alternative design will be proposed in the following sections.

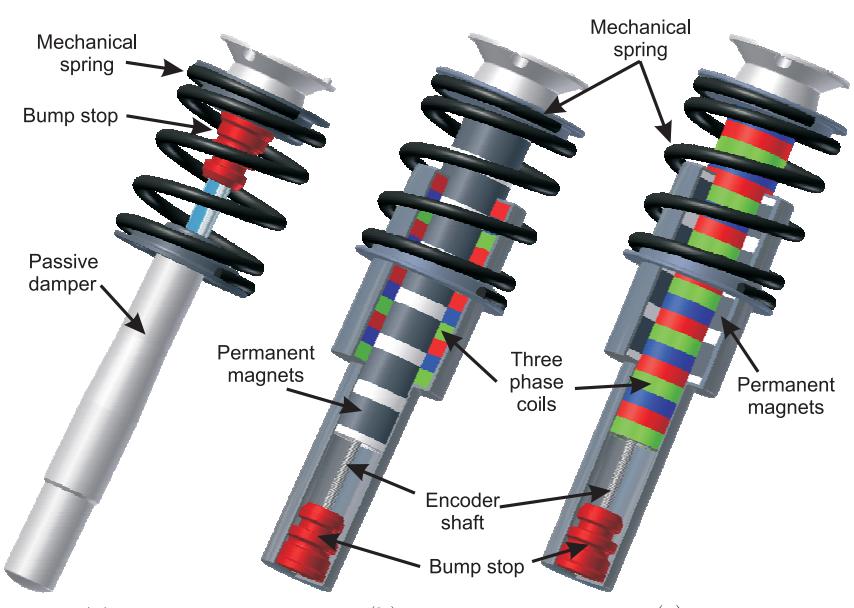

(a)

(b)

(c)

Fig. 8. Suspension struts: (a) passive, (b) active, interior magnet TPMA, (c) active, exterior magnet TPMA.

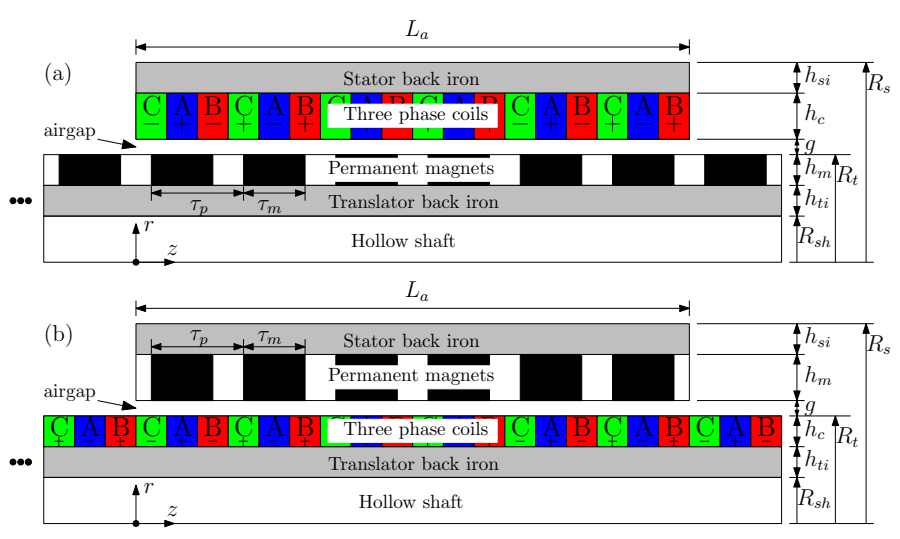

Fig. 9. Schematic view of slotless TPMA: (a) interior magnet, (b) exterior magnet.

\section{SUSPENSION DESIGN AND ACTUATOR CONSTRAintS}

\section{A. Suspension design}

In Fig. 8 (a) the passive suspension system is shown which consists of a mechanical spring in parallel with a passive hydraulic or pneumatic damper. The proposed electromagnetic active suspension strut is shown in Fig. 8 (b) and (c) which both consist of a slotless brushless three phase TPMA in parallel with a mechanical spring. Due to the ease in modeling, design and fabrication, the low force ripples and low cost, a slotless TPMA is preferred over a slotted one. Two different topologies are considered for the actuator, interior and exterior magnet as shown in Fig. 8 (b) and (c), respectively, and the cross sections are shown in Fig. 9 (a) and (b), respectively. The exterior magnet topology offers the benefit of the absence of a cable slap, however in order to keep the power level to a minimum, switching of coil sets should be implemented based upon position monitoring. Since this is also necessary for commutation in order to have long-stroke movement, a linear encoder is embedded in the hollow shaft. 
TABLE IV

ACTUATOR CONSTRAINTS

\begin{tabular}{|l|l|}
\hline Constraint & Description \\
\hline $0<L_{a}<200 \mathrm{~mm}$ & Length of the stator \\
$R_{s h}<R_{t}<35 \mathrm{~mm}$ & Radius of the translator \\
$R_{t}+g<R_{s}<60 \mathrm{~mm}$ & Radius of the stator \\
$R_{\text {sh }}>20 \mathrm{~mm}$ & Radius of hollow shaft \\
$0<P_{\text {int }}<193 \mathrm{~W}$ & Power for the interior magnet topology \\
$0<P_{\text {ext }}<143 \mathrm{~W}$ & Power for the exterior magnet topology \\
$0<B_{\text {iron }}<1.5 \mathrm{~T}$ & Flux density in the iron \\
\hline
\end{tabular}

\section{B. Volume and mass constraints}

The active suspension strut is designed to replace the passive one and as a result, the outer radius of the translator and the outer radius and length of the stator, have an upper constraint. There is a minimum constraint on the radius of the hollow shaft since a linear encoder is embedded. The moving mass should be limited to $16 \mathrm{~kg}$, however considering the available volume, this is not a hard constrained and is therefore easily achieved. The housing of the strut is made of aluminum for its low weight, high thermal conductivity and non magnetic properties.

\section{Thermal constraints}

Since the objective in design is to maximize the force, the actuator design always tends to have the maximum outer radius and length, and if not, aluminum is added in order to increase the heat convection and hence the performance. The air gap length, $g$, is fixed to $1 \mathrm{~mm}$ since sliding bearings will be used and hence, the thermal behavior of the actuator changes slightly by varying the other parameters and magnetization profile, hence the maximum copper losses can be obtained for a maximum temperature increase of $80^{\circ} \mathrm{C}$. Using a $2 \mathrm{D}$ thermal finite element model, the temperature distribution is calculated where a distinction is made between the interior and exterior magnet topology due to the difference in the temperature distribution, see Fig. 10. The temperature increment is calculated as function of the copper losses which is plotted in Fig. 11 for interior and exterior magnet topologies. It can be observed that the maximum copper losses are $193 \mathrm{~W}$ and $143 \mathrm{~W}$ for the interior and exterior magnet topology, respectively, for a maximum increment of $80^{\circ} \mathrm{C}$. A list of all the constraints is given in Table IV

\section{ACTUATOR MODELING, OPTIMIZATION AND DESIGN}

\section{A. Magnetostatic design}

In this section, an actuator design will be derived according to the specifications and constraints mentioned in previous sections. Both interior and exterior magnet topologies are considered, see Fig. 9 (a) and (b) respectively, for three different magnetization patterns, radial, Halbach and axial magnetization. It should be noted that for Halbach and axial magnetization the back iron for the magnets vanishes, $h_{t i}=0$ or $h_{s i}=0$ for interior and exterior magnet, respectively. Modeling of the magnetic field, $\mathbf{B}$, inside the air gap is performed using the analytical framework proposed in [6], [13], hence end effects of the finite length of the stator and

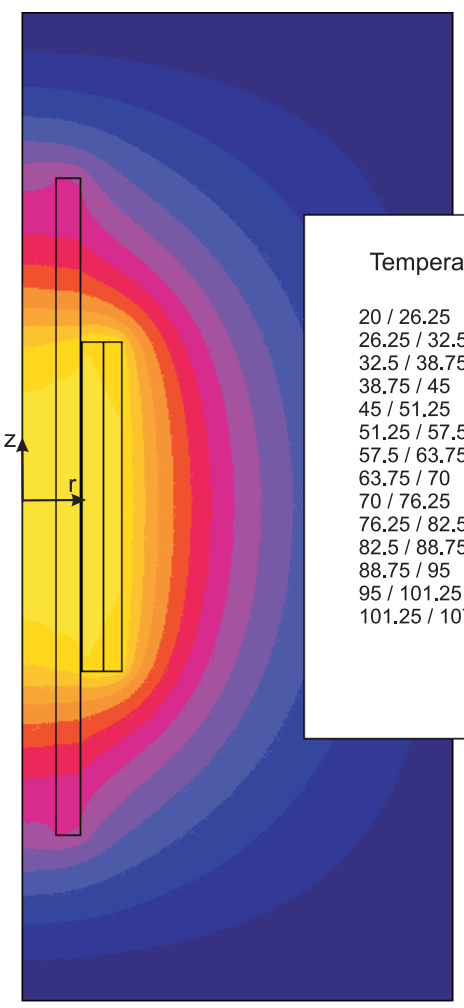

(a)

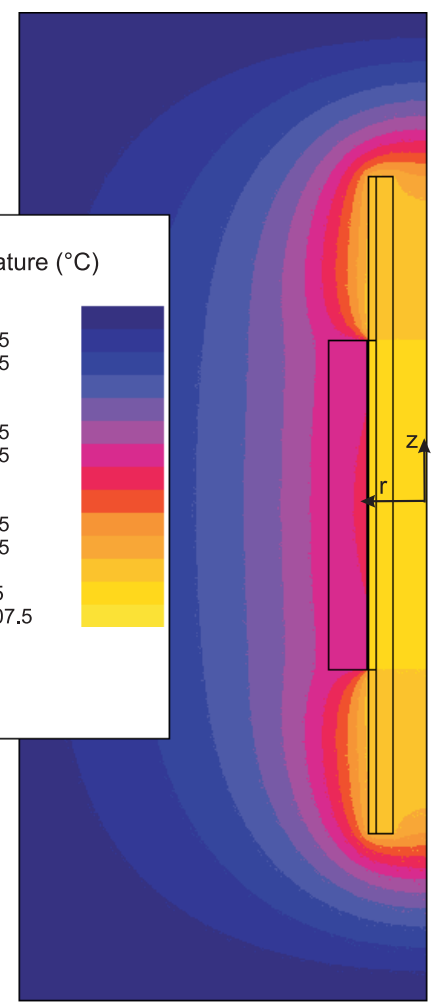

(b)
Fig. 10. Temperature distribution of (a) the interior magnet topology and (b) the exterior magnet topology (Halbach magnetization).

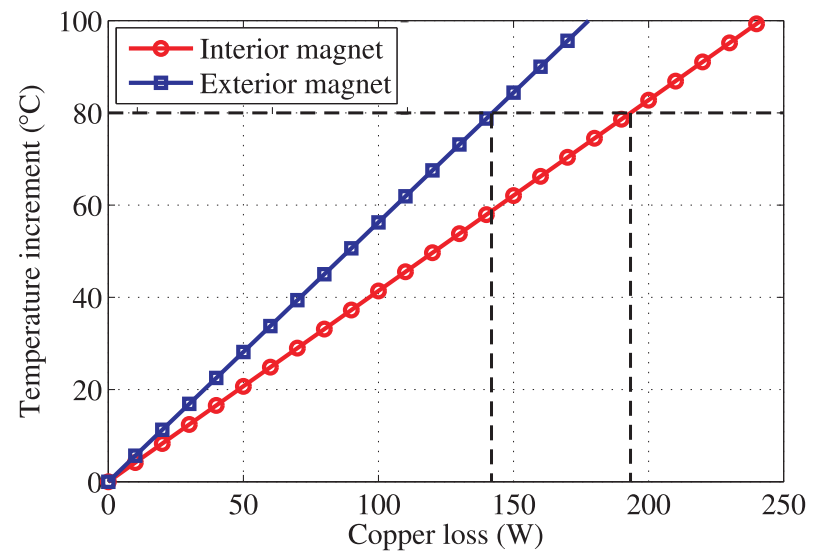

Fig. 11. Temperature increment of the actuator as function of the copper losses.

translator are neglected. Calculation of the force is obtained using the Lorentz equation at the center of the air gap and coil region, $R_{a g}$.

$$
\begin{aligned}
F_{a c t} & =\int_{V} \mathbf{J} \times \mathbf{B} d V, \\
& =\left.2 \pi R_{a g} \int_{0}^{L_{a c t}} J_{s} B_{r} d z\right|_{r=R_{a g}},
\end{aligned}
$$

where $J_{s}=h_{c} J$ is the surface current density and $B_{r}$ the radial component of the magnetic field at the mean air gap 
TABLE V

FINAL DESIGN OF THE EXTERIOR HALBACH MAGNETIZED TUBULAR PERMANENT MAGNET ACTUATOR.

\begin{tabular}{|l|l|}
\hline Variable & Value \\
\hline$N_{p}$ & 4 \\
$\alpha_{p}$ & 0.522 \\
$\tau_{p}$ & $25.0 \mathrm{~mm}$ \\
$h_{t i}$ & $10.5 \mathrm{~mm}$ \\
$h_{m}$ & $24.0 \mathrm{~mm}$ \\
$h_{c}$ & $4.46 \mathrm{~mm}$ \\
$J_{r m s}$ & $5.10 \mathrm{~A} / \mathrm{mm}^{2}$ \\
\hline
\end{tabular}

radius, $R_{a g}$, which is given by

$$
\begin{aligned}
& R_{a g}=R_{t}+\frac{g+h_{c}}{2} \text { for interior magnet, } \\
& R_{a g}=R_{t}+\frac{g-h_{c}}{2} \text { for exterior magnet. }
\end{aligned}
$$

Optimization is performed with sequential quadratic programming, where the objective is to maximize the force within the volume and power constraints. The optimization is performed for the three magnetization patterns, for interior and exterior magnet topologies and for different number of pole pairs, $1 \leq N_{p} \leq 5$.

In Fig. 12 and 13, the force level of the optimized interior magnet and exterior magnet topologies are shown, respectively, for different values of the pole pair number, $N_{p}$. It can be observed that for a low pole pair number the force levels are relatively low since the saturation level of the back iron (see Table IV) is the limiting constraint. Halbach magnetization is has the highest force levels since no back iron for the magnets is necessary compared to radial magnetization and hence, a higher magnet height is possible which increases the magnetic loading, B, and as a result the force level (6). Compared to axial magnetization, Halbach magnetization has a higher force level since the magnetic field is concentrated on the air gap side and due to the absence of iron pole pieces it is not limited by saturation levels. Another interesting observation is that for Halbach magnetization, the exterior magnet topology offers a higher force level compared to the interior magnet topology since a higher magnet height is possible, increasing $\mathbf{B}$, while the electrical loading is slightly decreased (due to thermal limitations), which is beneficial considering the total power consumption of the system. Hence, although the allowed copper losses are $50 \mathrm{~W}$ less due to thermal limitations, the force level is increased with $67 \mathrm{~N}$. However, this does not hold for axial magnetization since in this case the flux is not completely focused on the air gap side and there is a lot of leakage to the exterior of the actuator, see Fig. 14. The final design is therefore chosen to be an exterior Halbach magnetized topology with a mean force level of $755 \mathrm{~N}$, the flux density distribution of the full actuator is given in Fig. 15 and the final sizes are given in Table V. The rms current density to obtain the force profile of Fig. 16 is $5.1 \mathrm{~A} / \mathrm{mm}^{2}$. The force-current characteristic is linear up to $4.5 \mathrm{kN}$ and the necessary rms current density to obtain the peak force of 4 $\mathrm{kN}$ is $J_{r m s_{m}}=25.6 \mathrm{~A} / \mathrm{mm}^{2}$.

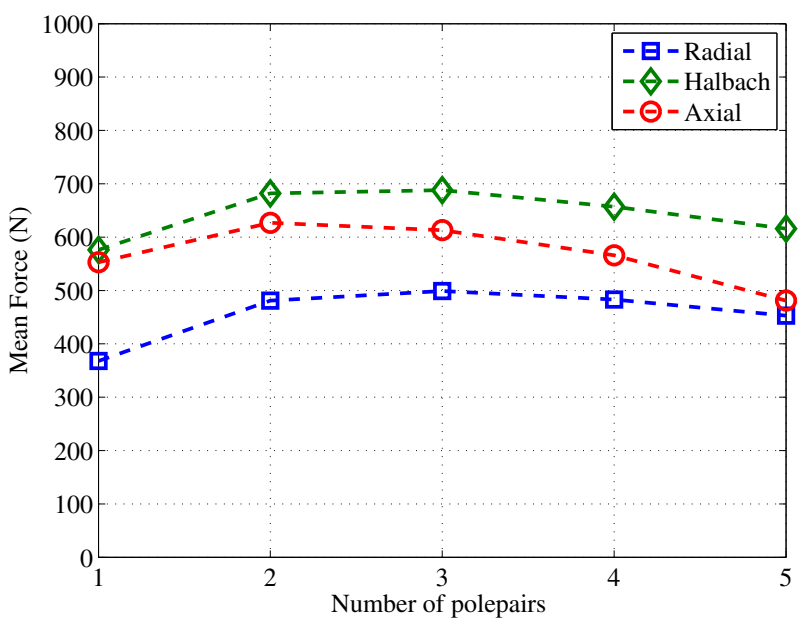

Fig. 12. Mean force level of the optimized interior magnet topologies for different pole pair numbers.

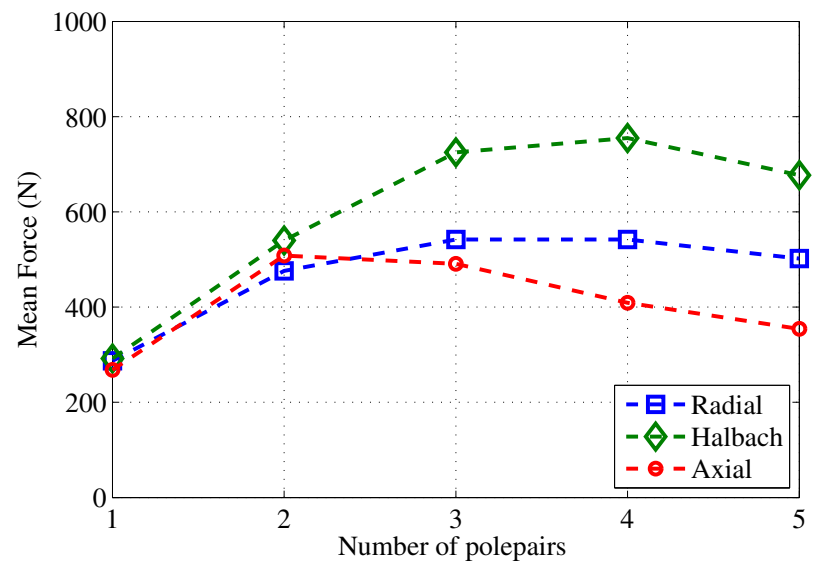

Fig. 13. Mean force level of the optimized exterior magnet topologies for different pole pair numbers.

\section{B. Dynamic design}

In this section the number of turns, $N$, will be determined based upon previous derived current density levels, speed specifications and available supply voltages, $V_{D C}$. The losses of the power electronics are neglected as well as the iron losses. The maximum value of the current, $I_{m}$, can be related to the maximum rms current density by

$$
I_{m}=\frac{\sqrt{2} J_{r m s_{m}} S_{c}}{N P_{f}}
$$

with $S_{c}=\frac{h_{c} \tau_{p}}{3}$ the coil area and $P_{f}=0.5$ the packing factor. The electromotive force (EMF), $e_{p h_{N}}$, per turn per phase is calculated with 2D FEA including end effects at a rated speed of $1 \mathrm{~m} / \mathrm{s}$ and shown in Fig. 17. From this, the peak EMF is related to the number of turns, $N$, and the armature velocity, $v$, by

$$
E_{m}=K_{E_{N}} v N
$$




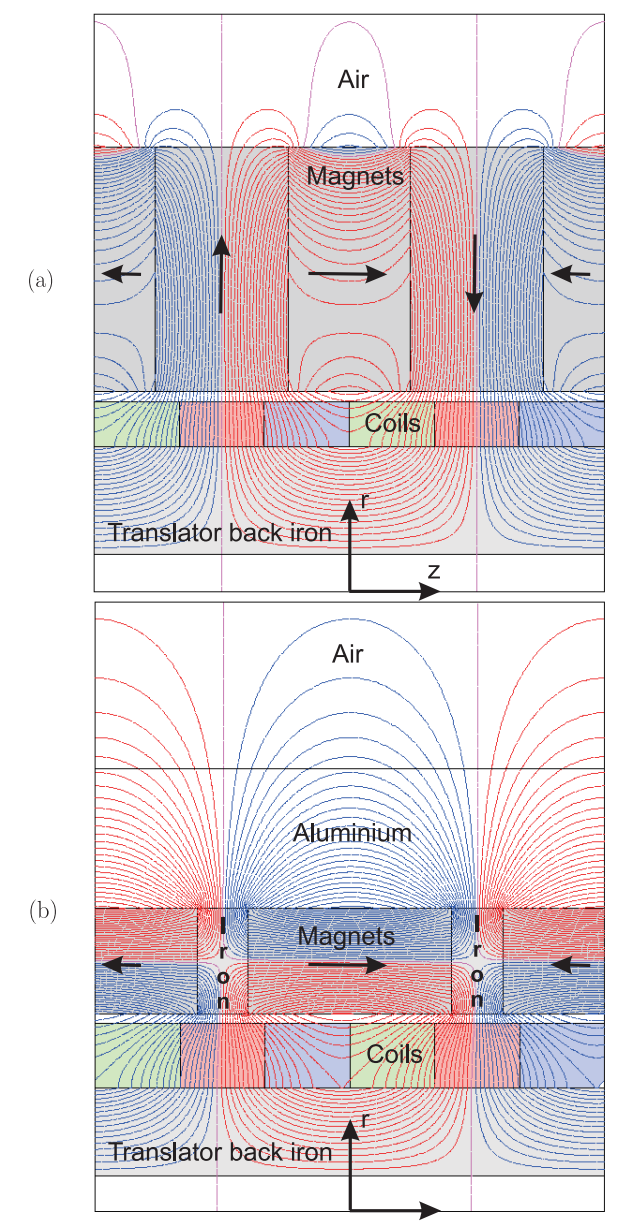

Fig. 14. Flux distribution of (a) the exterior Halbach magnetized topology and (b) the exterior axial magnetized topology $\left(N_{p}=4\right)$.

where $K_{E_{N}}=1.88 \mathrm{Vs} / \mathrm{m}$ as observed from Fig. 17. Furthermore, the synchronous inductance per turn is calculated which is $L_{s_{N}}=1.9 \mu \mathrm{H}$. Therefore, the reactance voltage can be written as

$V_{L_{m}}=\omega L_{s_{N}} N^{2} I_{m}=\frac{\pi v}{\tau_{p}} L_{s_{N}} N^{2} I_{m}=\frac{\sqrt{2} \pi J_{r m s_{m}} S_{c} v L_{s_{N}} N}{\tau_{p}}$.

The ohmic voltage drop can be written as

$$
\begin{aligned}
V_{R_{m}}=R_{p h} I_{m} & =\frac{4 \pi R_{c} \rho N_{p}}{S_{c} P_{f}} N^{2} I_{m} \\
& =\frac{4 \sqrt{2} \pi J_{r m s_{m}} R_{c} \rho N_{p} N}{P_{f}},
\end{aligned}
$$

where $R_{c}$ is the mean radius of the coil and $\rho$ the specific resistance. Due to commutation, the stator current is in phase with the induced EMF and based upon the phasor diagram in the $d-q$ reference frame, the various voltages are related to the phase voltage, $V_{m}$, as

$$
V_{m}^{2}=\left(E_{m}+V_{R_{m}}\right)^{2}+V_{L_{m}}^{2}
$$

where $V_{m}=\frac{V_{D C}}{\sqrt{3}}$ for space vector pulse width modulation. Considering a DC supply voltage, of $14 \mathrm{~V}, 42 \mathrm{~V}$ or $500 \mathrm{~V}$

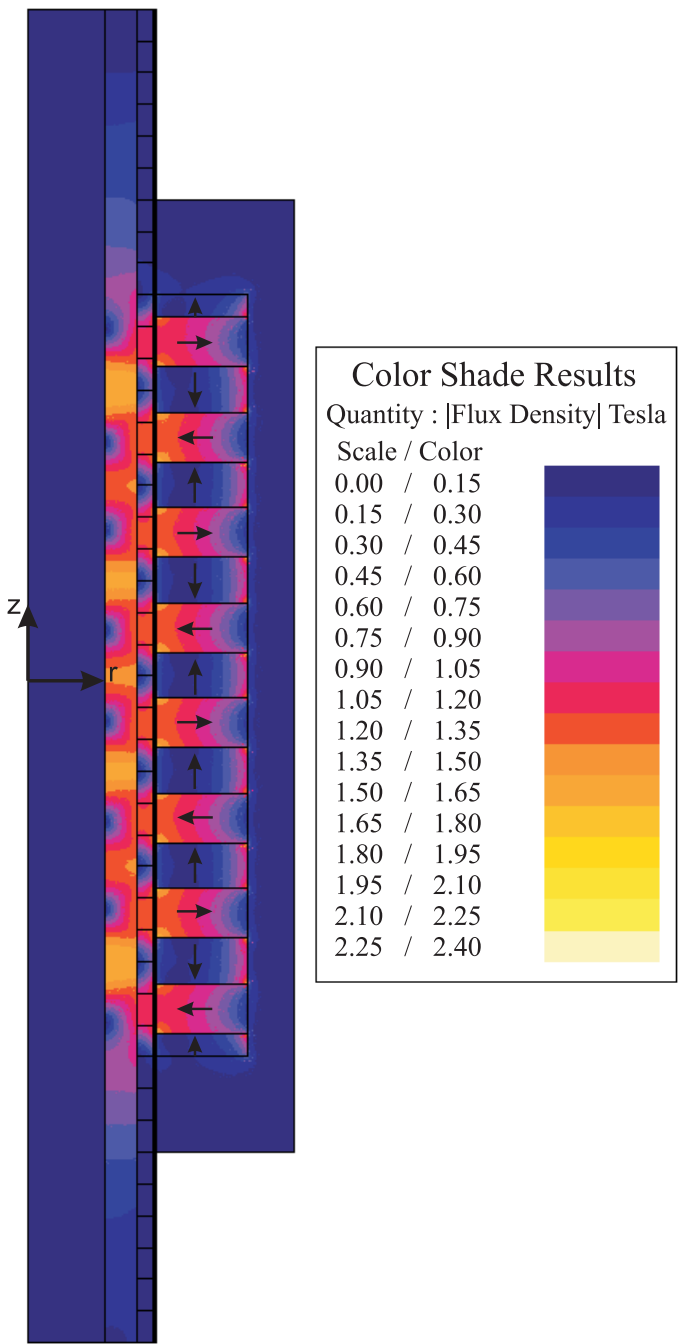

Fig. 15. Flux density in the exterior Halbach magnetized tubular permanent magnet actuator.

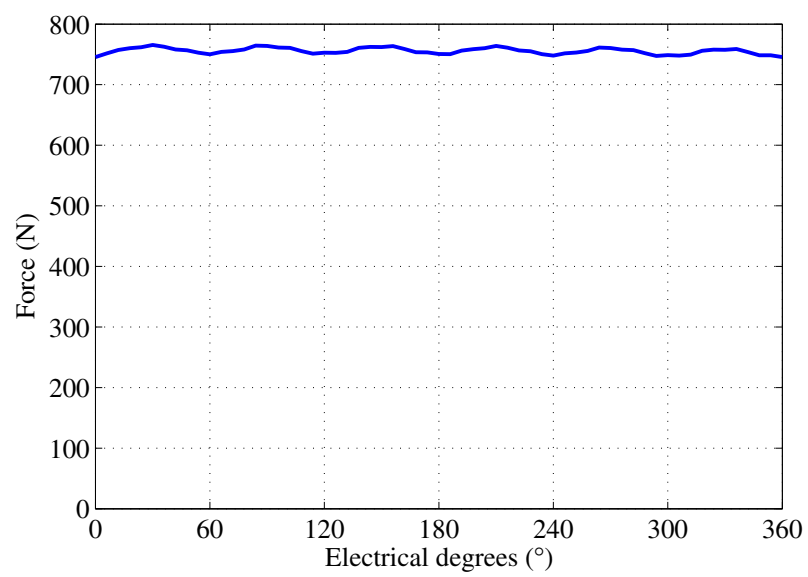

Fig. 16. Force profile of the exterior Halbach magnetized tubular permanent magnet actuator. 


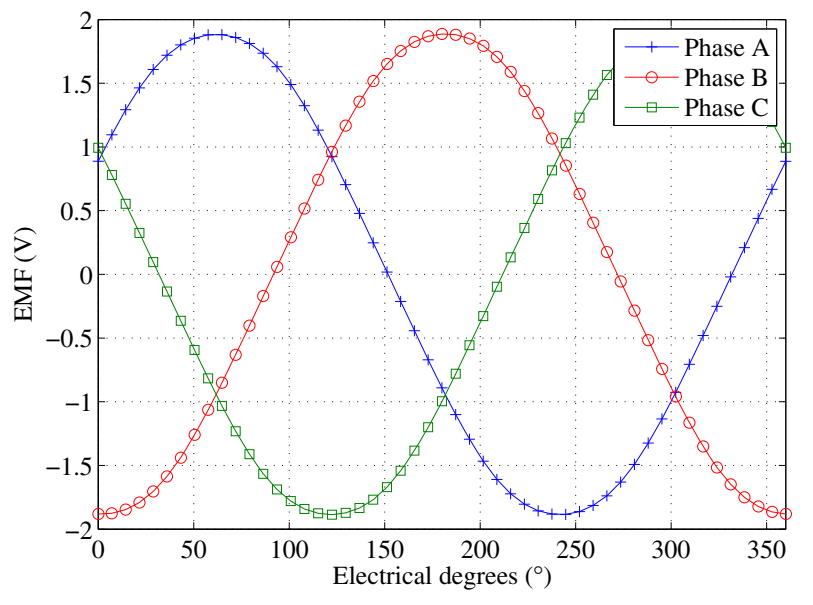

Fig. 17. Electromotive force of the final design of the exterior Halbach magnetized tubular permanent magnet actuator at $v=1 \mathrm{~m} / \mathrm{s}$.

TABLE VI

CIRCUIT PARAMETERS FOR DIFFERENT SUPPLY VOLTAGES.

\begin{tabular}{|l|l|l|l|l|l|}
\hline$V_{D C}$ & $N$ & $I \operatorname{rms}(755 \mathrm{~N})$ & $I \max (4 \mathrm{kN})$ & $R_{p h}$ & $L_{s}$ \\
\hline $14 \mathrm{~V}$ & 3 & $126 \mathrm{~A}$ & $634 \mathrm{~A}$ & $3.11 \mathrm{~m} \Omega$ & $17.1 \mu \mathrm{H}$ \\
$42 \mathrm{~V}$ & 9 & $42.1 \mathrm{~A}$ & $212 \mathrm{~A}$ & $28.1 \mathrm{~m} \Omega$ & $154 \mu \mathrm{H}$ \\
$500 \mathrm{~V}$ & 114 & $3.32 \mathrm{~A}$ & $28.1 \mathrm{~A}$ & $4.50 \Omega$ & $24.7 \mathrm{mH}$ \\
\hline
\end{tabular}

(hybrid vehicle), the number of turns and values of the current are given in Table VI. It can be observed that for the low supply voltages ( $14 \mathrm{~V}$ and $42 \mathrm{~V}$ ), the number of turns is very low due to the limitations on the induced EMF. This results of course in extreme high current values, especially for obtaining the peak force, which requires expensive power electronic converters and relatively thick wiring which is not preferred for automotive applications. Therefore, the actuator should have a higher force density and perhaps a slotted actuator would be more preferable. However, the low number of turns results in a low inductance and therefore a high bandwidth performance.

\section{CONCLUSION}

This paper described the design aspects for an electromagnetic active suspension system capable of eliminating roll and pitch behavior while maintaining damped behavior of the road vibrations in automotive applications. First, based upon measurements during a test drive on the Nürburgring with a BMW 530 with a passive suspension system, static and dynamic specifications are drawn. The proof of principle is shown on a quarter car test setup which mimics the roll and pitch behavior. Comparison of the passive and proposed active electromagnetic suspension system showed the improved performance where a minimization of $94.4 \%$ of the passive roll angle is achieved. Since the used electromagnetic suspension system does not meet the volume and mass requirements, an alternative design is proposed. The magnetostatic design is based upon optimization of the static force of a slotless actuator structure for different magnetization topologies as well as for interior and exterior magnet solutions. Overall, Halbach magnetization offers the highest force density where for the given geometry specifications, the exterior Halbach magnetized topology with four pole pairs is the optimal one. Although it is found that the exterior Halbach magnet topology offers a higher force density compared to the interior one, this does not hold for axial magnetization. Inverting the axial magnetization structure results in a large amount of leakage flux to the exterior of the actuator. The final design is capable of providing a continuous force of $755 \mathrm{~N}$ at a maximum speed of $1 \mathrm{~m} / \mathrm{s}$ and a maximum force of $4 \mathrm{kN}$ at $0.1 \mathrm{~m} / \mathrm{s}$. Due to the low number of turns, a low inductance is obtained which results in a high bandwidth performance. However, for the low voltage applications, relatively large currents are necessary which results in expensive power electronic converter and hence a slotted actuator with a higher force density is more preferred.

\section{REFERENCES}

[1] R. Rajamani and J. K. Hedrick, "Performance of active automotive suspensions with hydraulic actuators: theory and experiment," American control conference, vol. 2, pp. 1214 - 1218, June 1994.

[2] Y. M. Sam and K. Hudha, "Modelling and force tracking control of hydraulic actuator for an active suspension," 1st IEEE Conference on Industrial Electronics and Applications, pp. 1-6, 24-26 May 2006.

[3] S. Guo, S. Li, and S. Yang, "Semi-active vehicle suspension systems with magnetorheological dampers," IEEE International conference on vehicular electronics and safety, pp. 403-406, 13-15 Dec 2006.

[4] S. Guo, S. Yang, and C. Pan, "Dynamic modeling of magnetorheological damper behaviors," Journal of Intelligent Material Systems and Structures, vol. 17, no. 1, pp. 3-14, 2006.

[5] Delphi corperation. [online]. Available: http://delphi.com/.

[6] J. Wang, G. W. Jewell, and D. Howe, "A general framework for the analysis and design of tubular linear permanent magnet machines," IEEE Transactions on Magnetics, vol. 35, no. 3, pp. 1986-2000, May 1999.

[7] — "Design optimisation and comparison of tubular permanent magnet machine topologies," IEE Proceedings on Electrical Power Applications, vol. 148, no. 5, pp. 456-464, September 2001.

[8] J. J. H. Paulides, L. Encica, E. A. Lomonova, and A. J. A. Vandenput, "Design considerations for a semi-active electromagnetic suspension system," IEEE Transactions on Magnetics, vol. 42, no. 10, pp. 34463448, October 2006.

[9] J. L. G. Janssen, J. J. H. Paulides, E. A. Lomonova, and A. J. A. Vandenput, "Cogging force reduction in tubular permanent magnet actuators," IEEE Int. Electric Machines and Drives Conference (IEMDC'07), vol. 1, pp. 266-271, May 2007.

[10] J. C. Dixon, Tires, Suspension and Handling. U.K.: Cambridge University Press., 1996.

[11] I. Martins, J. Esteves, G. D. Marques, and F. P. da Silva, "Permanentmagnets linear actuators applicability in automobile active suspensions," IEEE Transactions on vehicular technology, vol. 55, no. 1, pp. 86-94, January 2006.

[12] California Linear Drives, Inc., User's Manual Linear Motors, UM-102 revision B ed., 2236 Rutherford Road, Ste. 119 Carlsbad, CA 92008, November 2005.

[13] J. Wang and D. Howe, "Design optimization of radially magnetized , iron-cored, tubular permanent-magnet machines and drive systems," IEEE Transactions on Magnetics, vol. 40, no. 5, pp. 3262-3277, September 2004 . 